\title{
Driven to succeed: improving adolescents' driving behaviors through a personal narrative-based psychosocial intervention in Serbia
}

\author{
Rimal, Rajiv N ; Yilma, Hagere ; Ryskulova, Nargis ; Geber, Sarah
}

\begin{abstract}
Globally, more adolescents die from road traffic fatalities than from any other cause, and males are significantly more vulnerable than females. Driver education interventions directed at males are less likely to succeed than those directed at females, and stronger optimistic bias and overconfidence bias have been implicated as likely reasons. We report results from a quasi-experiment conducted in Serbia, targeting male and female adolescents. Stratified by size, forty schools were randomly assigned to either a personal-narrative intervention or a no-intervention control arm. Data were collected before the intervention $(\mathrm{N}=1449)$ and again six months later $(\mathrm{N}$ = 1072). Risk perceptions improved for both males and females, and injunctive norms improved for females. Improvements in overconfidence bias and descriptive norms were predictive of improvements in high-risk driving behaviors. A significant interaction between improvements in injunctive norms and the intervention revealed that males whose injunctive norms improved were significantly more likely to be affected by the intervention, compared to the other groups. Implications for interventions are discussed.
\end{abstract}

DOI: https://doi.org/10.1016/j.aap.2018.09.034

Posted at the Zurich Open Repository and Archive, University of Zurich ZORA URL: https://doi.org/10.5167/uzh-158388

Journal Article

Accepted Version

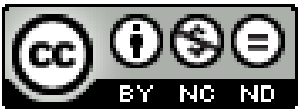

The following work is licensed under a Creative Commons: Attribution-NonCommercial-NoDerivatives 4.0 International (CC BY-NC-ND 4.0) License.

Originally published at:

Rimal, Rajiv N; Yilma, Hagere; Ryskulova, Nargis; Geber, Sarah (2019). Driven to succeed: improving adolescents' driving behaviors through a personal narrative-based psychosocial intervention in Serbia. Accident Analysis Prevention, 122:172-180.

DOI: https://doi.org/10.1016/j.aap.2018.09.034 
Driven to Succeed:

Improving Adolescents' Driving Behaviors through a Personal Narrative-Based Psychosocial Intervention in Serbia

\author{
Rajiv N. Rimal \\ George Washington University \\ rrimal@gwu.edu \\ Hagere Yilma \\ George Washington University \\ hyilma@gwmail.gwu.edu \\ Nargis Ryskulova \\ The World Bank \\ nryskulova@worldbank.org \\ Sarah Geber
}

Hanover University of Music, Drama, and Media sarah.geber@ijk.hmtm-hannover.de 


\begin{abstract}
Globally, more adolescents die from road traffic fatalities than from any other cause, and males are significantly more vulnerable than females. Driver education interventions directed at males are less likely to succeed than those directed at females, and stronger optimistic bias and overconfidence bias have been implicated as likely reasons. We report results from a quasi-experiment conducted in Serbia, targeting male and female adolescents. Stratified by size, forty schools were randomly assigned to either a personal-narrative intervention or a nointervention control arm. Data were collected before the intervention $(N=1,449)$ and again six months later $(N=1,072)$. Risk perceptions improved for both males and females, and injunctive norms improved for females. Improvements in overconfidence bias and descriptive norms were predictive of improvements in high-risk driving behaviors. A significant interaction between improvements in injunctive norms and the intervention revealed that males whose injunctive norms improved were significantly more likely to be affected by the intervention, compared to the other groups. Implications for interventions are discussed.
\end{abstract}

Keywords: adolescent driving, risk perception, overconfidence bias, descriptive norms, injunctive norms 


\section{Driven to Succeed:}

\section{Improving Adolescents' Driving Behaviors through a Personal Narrative-Based}

\section{Psychosocial Intervention in Serbia}

Road traffic injuries are a global public health problem. The World Health Organization (WHO, 2017) reports 1.25 million road traffic deaths per year, with the highest road traffic fatality rates in middle- and low-income countries. Road traffic-related deaths are more common than suicide, HIV, or homicide (WHO, 2017; see also Clarke, Ward, \& Truman, 2005). Across all countries, young drivers in particular constitute a high-risk group of road users (WHO, 2017). Per 100,000 inhabitants, two to three times as many people aged between 18 and 24 die in cars, compared to those aged between 25 and 65 (Promising Consortium, 1998).

Youth road fatalities have a strong gender component, as young males are at particularly high risk. About three quarters of all road traffic deaths occur among young males under the age of 25 years (WHO, 2017). Young males are three times as likely to be killed in road crashes, compared to young females (Massie, Campbell, \& Williams, 1995; Santamariña-Rubio, Pérez, Olabarria, \& Novoa, 2014). Moreover, in comparison to females, males are more likely to be involved in crashes as a driver (Turner \& McClure, 2003), and they are more likely to engage in higher-risk road behaviors, such as speeding, driving under the influence of alcohol, nonuse of seat-belts, and distracted driving (Harré, Field, \& Kirkwood, 1996; Rhodes \& Pivik, 2011). Given that gender is a consistent and important predictor across different road traffic risk behaviors, we adopt a gender-based perspective to examine predictors of road traffic risk behaviors and intervention effects.

We report results of an intervention conducted among young drivers in Serbia, a middle-income European country. In 2015, Serbia registered 90 deaths per million inhabitants, which is lower than rates in Romania and Bulgaria (both had 95 deaths per million) but significantly higher than the average rate in the European Union (51.5 deaths per 
million; European Commission, 2016; ITF, 2017; WHO, 2015). The intervention sought to lower young drivers' risk behaviors by shifting behavioral determinants particularly important in adolescence: risk perceptions and overconfidence bias (e.g., Matthews \& Moran, 1986; Tränkle, Gelau, \& Metker, 1990) as well as normative perceptions regarding peers' risk behaviors (e.g., Cestac, Paran, \& Delhomme, 2011; Møller \& Haustein, 2014).

\section{Underestimated Risk Perceptions and Overconfidence Bias}

Individuals' risk judgments are fundamental components of theoretical models of health behavior, including the health belief model (Janz \& Becker, 1984; Rosenstock, 1974), protection motivation theory (Rogers, 1983), and the extended parallel process model (Witte, 1992). Applied to road traffic, risk perception refers to people's subjective assessments about the likelihood of getting into a crash or being the victim of one (Harré, 2000). Hence, application of behavioral theories to adolescents' road safety practices implies that, to promote safer behaviors, interventions need to convince adolescents that they are at risk. This is not easily done, for two reasons identified in the literature.

Optimistic bias (Weinstein, 1982, 1987), the tendency to perceive oneself as being invulnerable relative to others, is one reason interventions encounter difficulties in elevating risk perceptions. Optimistic bias in road traffic behaviors tends to be particularly high among adolescents because they consider themselves less likely to get into a crash than their peers (Deery, 1999; DeJoy, 1989; Delhomme, Verlhiac, \& Martha, 2009; Harré, Foster, \& O'Neill, 2005; Matthews \& Moran, 1986; Tränkle et al., 1990). There is some evidence that optimistic bias can be reduced by reducing the social distance between the targeted individual and the referent other being used as the anchor for risk assessments (Lapinski, Rimal, Klein, \& Shulman, 2009; Rimal \& Morrison, 2006), but doing so has not been linked with reductions in risk behaviors. 
Sensation seeking is another reason why adolescents' risk perceptions are difficult to raise (Arnett, 1996). The very definition of sensation seeking, "the need for varied, novel, and complex sensations and experiences, and the willingness to take physical and social risks for the sake of such experiences" (Zuckerman, 1979, p. 10), captures the underlying idea, and it has been linked with reckless driving in a number of studies (Arnett, 1990, 1996; for a review, see Jonah, 1997). Sensation-seeking may serve as an explanatory variable, but the variance it explains in risk behaviors is often very small, revealed by a recent meta-analysis across 61 studies (Hittner \& Swickert, 2006). Moreover, the underlying idea is not very helpful for intervention design because, by definition, it is invariant. Tailoring different messages for individuals with different sensation seeking tendencies could be a strategy for interventions, because this technique can enhance message processing (Greene, Krcmar, Rubin, Walters, \& Hale, 2002), but there is little evidence about its efficacy in changing behavior.

We propose a third explanation, one based on adolescents' perceptions, often exaggerated, about their ability to engage in high-risk behaviors without the fallout. There is now an extensive literature on overconfidence bias, which is the almost universal tendency for individuals to believe their skills, judgments, and abilities are better than they actually are. This has been documented among a variety of professionals, including medical providers (Baumann, Deber, \& Thompson, 1991), real estate agents (Spence, 1996), judges (Budescu \& Rantilla, 2000), and statistical experts (Wagenaar \& Keren, 1985). A recent meta-analysis across 36 studies over a 40 -year period revealed almost a ubiquitously present overconfidence bias in clinical decision-making (Miller, Spengler, \& Spengler, 2015). Similar findings have also been reported in the domain of road safety (Ulen, 2005).

Exaggerated beliefs about one's own skills are associated with dangerous road traffic behaviors. Adolescents typically rate themselves as more skilled than their peers (Deery, 1999; DeJoy, 1989; Matthews \& Moran, 1986), underestimating their risk and overestimating their own driving skills (Gregersen, 1996). Although this overconfidence bias is seen in both 
males and females, it is greater among males who perceive their own behaviors to be less likely to result in accidents because of their exaggerated driving skills (DeJoy, 1990, 1992). In this paper, we hypothesize that this overconfidence bias and underestimated risk perceptions are associated with adolescents' high-risk driving intentions and we ask whether an intervention based on personal narratives can overcome some of these biases to affect driving intentions.

\section{Normative Perceptions}

There is now widespread acceptance in the literature that individually enacted behaviors have determinants at both the individual and social levels (Sallis \& Owen, 2015). Risk perception and overconfidence bias exist at the individual level. Social norms are important drivers of behaviors (albeit not the only ones) at the interpersonal and community levels (Rimal \& Lapinski, 2015). The importance of social norms in health (e.g., Eisenberg, Toumbourou, Catalano, \& Hemphill, 2014) is also emphasized in the theory of planned behavior (Ajzen, 1991), the theory of normative social behavior (Rimal \& Real, 2005), and the theory of normative conduct (Cialdini, Reno, \& Kallgren, 1990). Two different forms of norms have to be identified in the literature (Cialdini et al., 1990): descriptive and injunctive norms. Descriptive norms refer to the prevalence of a behavior within the referent group; injunctive norms refer to the social approval of the behavior by relevant others. Thus, the two types of norms can be thought of as norms regarding what is done (descriptive), as compared to norms of what ought to be done (injunctive; Deutsch \& Gerard, 1955; Kallgren, Reno, \& Cialdini, 2016).

With regard to road traffic behaviors, peers - most often defined as friends in social norms research (Shulman et al., 2017) - appear to be a more important reference group than other social groups (e.g., family) (Zhang, Wieczorek, \& Welte, 2012). Consequently, normative peer influences have been found for different road traffic behaviors, such as 
speeding (Cestac et al., 2011; Møller \& Haustein, 2014; Simons-Morton et al., 2012), drinking and driving (Åberg, 1993; Beck, 1981; Kenney, LaBrie, \& Lac, 2013; Zhang et al., 2012), and texting (Bazargan-Hejazi et al., 2017; Gauld, Lewis, \& White, 2014; Nemme \& White, 2010).

Social norms are useful gateways for affecting behaviors not only because they have been directly linked with behavioral changes (Cialdini et al., 1990; DeJong et al., 2006), but also because they themselves are amenable to change (Berkowitz, 2004; Rimal, Lapinski, Cook, \& Real, 2005). Individuals often harbor incorrect perceptions about both descriptive and injunctive norms in their social midst, resulting in a "mismatch between perceptions and reality" (Rimal \& Lapinski, 2015, p. 396) and overestimation of peers' permissiveness of attitudes and risk behaviors (e.g., Kenney et al., 2013; see also Berkowitz, 2004). This is an important point because it implies that, if these misperceptions can be corrected, the corresponding behaviors can be changed (Berkowitz, 2004). Lewis and Neighbors (2004) revealed that both males and females tend to overestimate their peers' risk behaviors and attitudes; however, further studies also showed that men perceive more permissive social norms than women (Adams \& Nagoshi, 1999) and that traditional masculine gender socialization and social norms models encourage men to put their health at risk (Mahalik, Burns, \& Syzdek, 2007).

\section{An Intervention on Perceived Risk, Overconfidence Bias, and Normative Perceptions}

Given the findings on gender-differences regarding road traffic risk behaviors and their determinants, this project's aim was to develop a gender-sensitive educational intervention with the intent to lower road traffic risk behaviors in youth by shifting their risk perceptions, reducing their overconfidence bias, and restructuring their normative perceptions.

Various interventions have been run to reduce optimistic bias related to young drivers' risk perceptions (Fisher, Pollatsek, \& Pradhan, 2006; Gregersen, 1996; White, Cunningham, 
\& Titchener, 2011; McKenna \& Myers, 1997), but only with meager results (see also White et al, 2011). The current approach differs from these intervention programs in two critical ways. First, in order to enhance risk perceptions and reduce overconfidence bias, we took advantage of the findings from the literature pertaining to the power of personal narratives in enhancing risk perceptions, particularly because such approaches are less affected by defensive message processing (De Wit, Das, \& Vet, 2008). This approach was further enhanced by using live role models similar in demographics and life experiences as the target audiences themselves. Second, the approach focused on the social contexts in which high-risk driving decisions are typically made among adolescents - whether to drink and drive after a party, driving recklessly in the presence of others, etc. In the intervention, first-person narratives were presented by victims of car crashes, who came to the classroom in their wheelchairs. They talked about their own overconfidence that led to the car crash, and they discussed the prevalence of such events among adolescent drivers, often in graphic detail.

There is some evidence that such driver education programs at schools can improve awareness of driving hazards. An education intervention carried out in Mexico targeting children and teenagers in public schools, for example, resulted in increased perception of danger regarding poor road use behaviors and increased sense of individual responsibility (Treviño-Siller, Pacheco-Magaña, Bonilla-Fernández, Rueda-Neria, \& Arenas-Monreal, 2017). With our combination of a risk perception intervention and a social norms approach, our intervention aimed to address risk perceptions, overconfidence bias, and normative beliefs in parallel.

Given the extant research, we assumed that lower risk perception, higher overconfidence bias, and lower pro-safety social norms would be associated with riskier driving intentions. Taking up a gender-specific perspective, the hypothesis is as follows: 
H1: Lower risk perception, higher overconfidence bias, lower pro-safety descriptive norms, and weaker pro-safety injunctive norms will be associated with greater high-risk driving intentions among both males and females.

Moreover, we hypothesized that the intervention would lower risky driving intentions in youth by heightening their risk perceptions, reducing their overconfidence bias, and restructuring their normative perceptions in favor of healthier norms. Consequently, from a gender-specific perspective, the hypotheses on the intervention effects are as follows:

$\mathrm{H} 2$ : The intervention group, in comparison to the control group, will display higher risk perceptions, lower overconfidence bias, greater descriptive and injunctive norms, and safer behavioral intentions among both males and females.

H3: Improvements in risk perceptions, overconfidence bias, and normative beliefs will be associated with improvements in behavioral intentions among both males and females.

\section{Method}

\section{Intervention Development}

We designed and implemented an intervention targeting adolescent students in Serbia. The intervention sought to enhance adolescents' risk perceptions, to make them believe that, despite their beliefs about personal invulnerability, they could be at risk. Other components of the intervention provided information about male and female behaviors and corresponding norms. These theory-informed ideas were first operationalized and tested through a formative assessment.

Formative Assessment. The formative assessment was conducted in Serbia by members of a research firm in Belgrade, selected through a national bidding process. It comprised the following components: (a) six focus group discussions: two among male students; two among female students; and two among male and female students; (b) two oneon-one interviews with teachers; (c) two one-on-one interviews with parents; and (d) two reaction interviews with male students and two reaction interviews with female students 
(reaction interviews were those in which interviewees listened and provided reactions to focus group discussion interviews conducted previously). Interviews focused on prior knowledge about road safety, barriers, myths, and high-risk behaviors, including drinking and driving, distracted driving, not using seatbelts or helmets, speeding, and disobeying traffic rules.

Recommendations from the formative assessment highlighted the importance of including real-life examples, referencing and linking with existing road safety examples on the Internet, using educators with first-hand experience with automobile crashes, adopting a gender-specific approach (for example, in how males and females are depicted in crashes, being sensitive about the gender of presenters and students), and being clear about the difference between trusting a driver and acting on behalf of one's own safety (based on a finding that students believed they did not have to wear a seatbelt if they trusted the driver).

The Intervention. Findings from the formative assessment were used to augment an ongoing intervention (in terms of both content and structure) run by members of the Association of Paraplegics and Quadriplegics of Serbia (SPIKS). Content-wise, the intervention was modified to address issues of trust, it used relevant examples, and it consistently referred to different experiences of male and female drivers and passengers. Structure-wise, the primary change made to the existing intervention was the inclusion of one male and one female narrator (which was not the case before this study was implemented).

The intervention used a first-person narrative approach and took place in Serbian high schools between November 2016 and May 2017. The campaign was presented by male and female individuals who had themselves suffered from adverse consequences of a road crash. Members of SPIKS provided the in-class presentations. The presentation emphasized genderspecific behaviors that put men and women at risk in different ways. For example, in Serbia, young males are drivers and young females are passengers significantly more often than vice versa (RSA, 2015). Furthermore, outcomes of crashes also have a gender component: Because of smaller body frames, female injuries from airbag deployment tend to be different from 
male injuries, as injuries due to lateral impact of air bags happen more often among females (Jakobsson, Isaksson-Hellman, \& Lindman, 2008; Viano, 2003).

\section{Evaluation Design}

We used a longitudinal quasi-experiment in which 20 schools in and around Belgrade were first aligned according to school size and then each of the two adjacent schools (on this size-based continuum) were randomly assigned to either the treatment schools or the control schools. The only factor that renders this study design a quasi-experiment, instead of a truly randomized trial, is that the selection of 20 schools was not done randomly from all available schools; rather, the 20 schools were those agreeing to participate in this study.

In each selected school, equal numbers of Grade 3 and Grade 4 (in the United States, this is equivalent to $11^{\text {th }}$ and $12^{\text {th }}$ year of school) classes were chosen for inclusion, by randomly selecting the particular classes when there were more than one to choose from. Students in the two grades were between 17 and 19 years of age. This age group was chosen so that the intervention would be delivered right before students began acquiring their driver's licenses. Baseline assessments were made in December, 2016, followed immediately by the intervention in the treatment schools, where immediate post-tests were conducted after the intervention (data from this immediate post-test are not reported in this paper). Six months later, in May, 2017, post-intervention assessments were made in both the treatment and control schools. In order not to withhold treatment, control schools also received the intervention after the second round of data collection.

\section{Procedures}

All assessments were done in classrooms, where students answered questions at their desks through a paper-and-pencil survey. In order to match their responses from pre- to postintervention, students provided their initials, date of birth, and gender, which were used to form a unique ID during both assessments. 


\section{Measures}

All measures were identical at both the pre- and post-intervention periods.

Risk Perception. Participants expressed their agreement on a five-point scale, ranging from "strongly disagree" to "strongly agree," with statements about their likelihood of getting into an accident if they engaged in eight high-risk behaviors, including speeding, texting while driving, talking on the phone, driving after drinking, reading a text, driving when sleeping, running a red light, and not stopping at a stop sign. Responses were averaged into an index $(\alpha=.84$ at pre and $\alpha=.88$ at post).

Overconfidence Bias. Overconfidence bias was operationalized as the extent to which respondents believed they could engage in the aforementioned eight high-risk behaviors without getting into an accident. They were presented with eight high-risk actions (similar to those used for risk perception) and asked to state how much they agreed that they could perform each of those actions "without getting into an accident." Responses, recorded on fivepoint scales, were averaged into an index ( $\alpha=.86$ at pre and $\alpha=.88$ at post).

Descriptive Norms. Descriptive norms were operationalized as the extent to which participants believed high-risk behaviors were prevalent among their peers. They were asked how much they agreed that their close friends engaged in (the same as above) eight high-risk behaviors. Responses, recorded on five-point scales, were averaged into an index ( $\alpha=.89$ at pre and $\alpha=.90$ at post). Responses were recoded such that higher values signified the belief that their peers were not engaging in high-risk driving behaviors (i.e. strong descriptive norms).

Injunctive Norms. Injunctive norms were operationalized as the extent to which participants believed their close friends would be upset with them if they engaged in (the same as above) eight high-risk behaviors. Responses, recoded on five-point scales, were 
averaged into an index $(\alpha=.88$ at pre and $\alpha=.89$ at post). Responses were recoded such that higher values signified stronger injunctive norms to support healthy (or low-risk) behaviors.

High-risk Driving Intentions. Because a majority of the participants had not already begun driving, we asked questions about their driving intentions (as opposed to actual driving behaviors). Specifically, we asked them to state how likely they would be to engage in six behaviors when driving a vehicle, (a) read an incoming text, (b) send a text, (c) talk on the phone using one of their hands, (d) exceed the speed limit by more than 15 kilometers per hour, (e) rush through a red light, and (f) go through a stop sign without stopping. Responses, recorded on five-point scales, were averaged into an index ( $\alpha=.79$ at pre and $\alpha=.82$ at post).

\section{Attrition}

In longitudinal studies, attrition often remains a concern. In our study, we started with $N=1,449$ students at pre and we were able to retain $N=1,072(74 \%)$ students at post. Attrition did not occur at random. On average, intention to engage in risky behaviors at pre was significantly higher among those who were lost to follow-up $(M=2.38, S D=0.87)$, compared to those who were retained $(M=2.26, S D=.84 ; t=2.37, \mathrm{p}=0.018)$. Retention in the treatment group was $77 \%$, whereas retention in the control group was $71 \%\left(\chi^{2}=6.84, p<\right.$ $.01)$.

\section{Results}

\section{Preliminary Analyses}

Table 1 shows the distribution of the sample in both treatment and control schools. On average, students were about 18 years old, and they were split evenly by gender.

Approximately 11 percent owned a license, but 23 percent reported having driven a car (likely because many were driving with a temporary permit). Most students had seen or been exposed to road safety campaigns previously and approximately half the students either had been in a 
car crash or knew a family member or a friend who had. Importantly, none of the background variables differed between the treatment and control schools.

\section{Hypothesis H1}

As a test of H1, Table 2 displays the results from a multiple linear regression in which demographic variables are used as the controls and the four psychosocial factors of interest (risk perception, overconfidence bias, descriptive norms, and injunctive norms) are used to predict high-risk driving intentions, separately for males and females.

As shown in Table 2, age and owning a driver's license were not associated with intentions. Among males $(\beta=-.09, p<.05)$, but not among females, having previously driven a vehicle was positively associated with high-risk driving intentions. Among both males $(\beta=$ $-.17, p<.001)$ and females $(\beta=-.16, p<.001)$, risk perceptions were negatively associated with high-risk driving intentions, meaning that those who had higher levels of risk perception were less likely to intend to engage in high-risk driving behaviors. Overconfidence bias was a significant predictor of high-risk driving intentions for both males $(\beta=.23, p<.001)$ and females $(\beta=.38, p<.001)$ : Those who believed they could get away with high-risk behaviors were more likely to intend to engage in such behaviors. Descriptive norms were significant predictors of high-risk driving intentions for both males $(\beta=-.34, p<.001)$ and females $(\beta=$ $-.27, p<.001$ ), such students were less likely to engage in high-risk driving behaviors if they believed that such behaviors was less common among their peers. Injunctive norms were not associated with high-risk driving behaviors for males or for females. Overall, the model was able to explain approximately 40 percent of the variance in driving intentions. H1 was supported for three (risk perception, overconfidence bias, and descriptive norms) of the four psychosocial factors (injunctive norms did not predict intentions). 


\section{Hypothesis $\mathbf{H 2}$}

Our second hypothesis predicted that improvements in the four psychosocial predictors (risk perception, overconfidence bias, descriptive norms, and injunctive norms) would be greater in the treatment than in the control schools. Results are shown in Table 3, in which we report differences in treatment schools from pre-intervention to post-intervention, compared against similar differences in control schools. Because of the directional hypothesis, tests are one-tailed.

The change in risk perception appears to have been significantly greater in treatment schools as compared to control schools $(t=1.87, p<.05$ for males and $t=2.0, p<.01$ for females). We also found that, for females, but not for males, there was a significant change in injunctive norms, which improved in both treatment and control schools, but the improvement was greater in treatment schools $(t=1.86, p<.05)$. We should also note that, for males, injunctive norms improved in both treatment $(t=1.73, p<.05)$ and control $(t=2.11, p<.01)$ schools, but this was likely due to secular trends, because the rate of increase was not greater in treatment schools. H2 was only partially supported.

\section{Hypothesis $\mathbf{H 3}$}

Our third hypothesis predicted that improvements in psychosocial factors would be associated with improvements in driving intentions. This hypothesis was tested in two ways. First, we ran zero-order Pearson correlations between differences in psychosocial factors (from post-intervention to pre-intervention) and behavioral intentions. Second, we conducted hierarchical linear regressions with high-risk driving intentions at post as the dependent variable. In the first step of the regression, we used pre-intervention intention as a predictor, thus controlling for the effect of prior intentions. In the second step, we added the demographic predictors. In order to test the effects of the change in psychosocial factors on behavioral intentions, we first computed the difference between the post-intervention and preintervention values for each psychosocial factor. In the third step of the regression, the 
differences between the post-intervention and pre-intervention values for each psychosocial factor were used as predictors of intentions. Finally, we also tested for interaction effects between treatment and differences in each of the psychosocial factors.

Zero-Order Pearson Correlations. Table 4 shows the zero-order Pearson correlations for both males (below the diagonal) and females (above the diagonal). As might be expected, pre-intervention intention was strongly associated with post-intervention intention $(r=.52, p<.001$ for males and $r=.50, p<.001$ for females). Changes in perceived risk were not associated with post-intervention intentions for both males and females, but changes in overconfidence bias were associated with intentions for both genders $(r=.22, p<$ .001 for males and $r=.20, p<.001$ for females), indicating that those whose overconfidence bias was reduced were less likely to harbor high-risk driving intentions. Change in descriptive norms were associated with high-risk driving intentions for both males and females $(r=-.14$, $p<.001$ for both genders), indicating that, over time, those who came to believe that most of their peers do not engage in high-risk behaviors were themselves likely to hold lower-risk intentions. Changes in injunctive norms were not associated with intentions. Finally, we also did not observe direct treatment effects for males or for females.

Regression Equations. Table 5 shows results from hierarchical regression equations in which post-intervention intentions are predicted by demographic variables, changes in psychosocial predictors, and the intervention, after first controlling for pre-intervention intentions. Approximately 30 percent of post-intervention intentions to engage in high-risk driving behaviors were explained by pre-intervention intentions among males; the corresponding figure among females was approximately 27 percent.

In the second step of the regression equation, we entered the three demographic variables (age, owning a license, and prior driving), but none of these variables was associated with intentions. 
Subsequently, we added the differences in psychosocial factors (from postintervention to pre-intervention). Changes in risk perception and changes in injunctive norms were not associated with intentions. However, differences in overconfidence bias and descriptive norms were associated with intentions for both males and females. Those who reduced their overconfidence bias (compared to those who increased their bias) were more likely to engage in lower-risk behaviors, and this was true for both males $(\beta=.21, p<.001)$ and females $(\beta=.25, p<.001)$. Similarly, those who, over time, came to believe that their peers engage in lower-risk behaviors were themselves more likely to engage in low-risk behaviors $(\beta=-.15, p<.001$ for males and $\beta=-.11, p<.01$ for females).

We did not observe a direct treatment effect for both males and for females.

We also tested four interactions: treatment multiplied by each of the four psychosocial variable differences (from pre-intervention to post-intervention) to determine whether effects of changes in risk perception, overconfidence bias, and norms were amplified by the intervention. The only interaction that was significant was that between the intervention and difference in injunctive norms, which was true for both males and females. The pattern of the underlying interaction is further shown in Figure 1. As displayed in the figure, males in control and treatment schools constituted the two groups with the highest-risk and lowest-risk intentions, respectively, with the female treatment and female control schools occupying positions in between. Among the four lines depicted in the figure, the slope of only one line that for males in treatment schools $(\beta=.13, p<.05)$ - was statistically significant, meaning that improvements in injunctive norms affected behavioral intentions in a positive manner only for the males who were exposed to the intervention; similar patterns were not found among any of the other three groups. 


\section{Discussion}

The purpose of this paper was two-fold. On a conceptual level, we sought to learn whether the combination of a risk perception intervention and a social norms approach would resonate with adolescents, particularly males who have typically been impervious to similar interventions in the past. On a practical level, given the difficulty prior campaigns have encountered in improving adolescents' (particularly males') road safety behaviors, we sought to determine whether a first-person narrative from victims of prior crashes could change adolescents' road safety intentions. Overall, our answer to both questions seems to be that interventions targeted at this population should expect only modest effects and that an injunctive norms-based appeal may have a slight edge. But even this tentative conclusion comes with important qualifiers, as we describe subsequently.

We first highlight the nature of the intervention itself so that we can contextualize the findings. Our intervention included a one-class (approximately 45 minutes in duration), inperson presentation made to 17 to 19 year-old students by a male and a female road crash victim. The impact evaluation assessed outcomes approximately six months later. Given the enormous developmental and adolescent-level changes taking place in this population, it is somewhat remarkable that there were lingering (and discernible) effects by the follow-up data collection period.

Among males, we found that risk perceptions were impacted by the intervention, but this impact did not, subsequently, affect behavioral intentions. Moreover, the intervention was not able to affect overconfidence bias, descriptive norms, or injunctive norms among males.

Among females, the intervention increased their risk perception and injunctive norms: changes in risk perception and injunctive norms in the treatment group were significantly greater than corresponding changes in the control group. Although female students' risk perceptions and injunctive norms improved, these improvements were not associated with intentions to engage in risky behaviors. 
These results are somewhat disheartening in that they show that the chain of underlying impact - from the intervention to psychosocial factors to behavioral intentions got truncated. The intervention affected risk perceptions for males and females and it also affected injunctive norms for females, but these outcomes did not translate into intentions. Furthermore, factors that were not affected by the intervention, namely overconfidence bias and descriptive norms, were themselves associated with behavioral intentions. In other words, we changed factors that were not relevant for the primary outcome (behavioral intention) but did not change factors that proved to be more relevant.

This does not mean, however, that our efforts were for naught, for we have learned a number of important lessons. First, we need to find creative ways of improving descriptive norms pertaining to the behavior of interest, as our results revealed that changes in normative perceptions significantly improved behavioral intentions for both males and females. Indeed, if people can be convinced that many others in their social midst are acting in healthy ways, they often follow suit (Cialdini et al., 1990), as has been found in a recent review of social norms (Chung \& Rimal, 2016). Many universities in the United States have adopted a "normative restructuring strategy" to reduce alcohol consumption on campus (see Berkowitz, 2004 for a review) by convincing students their peers drink less than widely perceived, and this approach seems to bear fruit (DeJong et al., 2006), although its efficacy is not demonstrably consistent (DeJong et al., 2009).

Second, we also found that an intervention focus on ways of reducing overconfidence bias may bear fruit. We operationalized overconfidence bias as the false sense of security that people may harbor in their perceived ability to engage in high-risk behaviors and remain impervious to negative outcomes, the extent to which one can "get away with" such behaviors. In our study, adolescents were asked about the extent to which they could speed, text, talk on the phone, drink alcohol, read a text message, be fatigued, run a red light, and not stop at a stop sign while driving and still avoid getting into an accident. We found this belief 
was not affected by the intervention, but changes in this belief over time were significant predictors of behavioral intentions for both males and females.

It is less clear how one reduces this bias, but social cognitive theory (Bandura, 1986) may provide some initial ideas, particularly in promoting vicarious learning by depicting role models (who are similar to the target audience) attenuating their levels of confidence because of negative outcomes they have encountered, despite their initial confidence. This is speculative, but the relationship we reported between reductions in overconfidence and behavioral intentions warrant further inquiry.

Third, it appears the window of influence available for reaching the group most resistant to change - young male drivers - may be provided through injunctive norms. We found that, among males who improved their injunctive norms, the intervention was successful in significantly improving their driving intentions. Indeed, this group showed the highest level of change, compared to the other three groups (males not exposed to the intervention and females both exposed and not exposed to the intervention). Put another way, although we do not know what factors led to improvements in males' injunctive norms, those whose norms were improved were more susceptible to the intervention's influence than any other group. This, of course, begs the question as to how one improves people's injunctive norms. Indeed, we are unable to find evidence in the literature demonstrating a successful change in injunctive norms through field interventions. This is likely because changing injunctive norms means altering what people already know to be true - the extent to which they feel pressure from their peers to behave in certain ways. Outside agents, like interventions, are rarely able to do this. Nevertheless, there may be creative strategies that appeal not to the target audience itself, but, perhaps, to the target's social network members. "Please remind your friend that you and others close to him/her disapprove of this behavior" may be one technique interventions can use. This, of course, remains to be tested. 
It is also worth discussing our findings with regard to risk perception. Risk perception, operationalized as perceived susceptibility and severity, is an important variable in the health belief model (Rosenstock, 1974), and it is thought to affect preventive behaviors because of humans' intrinsic motivations to remain healthy and avoid negative health outcomes. In our study, we did not find evidence that adolescents' perceptions of risk modulated their behaviors. Some scholars (see, for example, Weinstein \& Nicolich, 1993), noting that crosssectional studies are unable to disentangle risk perception as the cause of preventive behavior (as envisioned in the health belief model) from the effects of behaviors (e.g., those who enact healthy behaviors may, correctly, perceive lower risk perceptions), have urged researchers to undertake longitudinal research to study the relationship more rigorously. In this longitudinal study with a five-month lag period, we did not observe changes in risk perceptions to lead to changes in behavioral intentions. This was true for both males (whose risk perceptions were not altered by the intervention) as well as females (whose risk perceptions were heightened).

We should note that our dependent variable - behavioral intention - was deliberately chosen as the appropriate outcome for this study. This was because most of our participants were not yet drivers, which meant that asking them about actual driving behaviors would introduce its own set of biases. Indeed, for adolescents who are on the verge of acquiring their driver's license, interventions successfully able to improve their safe-driving intentions fulfill an important public health function. As we learned in this paper, doing so is not trivial.

In our regression models, we saw that almost 30 percent of the variance in intentions was due to prior intentions (from five months previously), suggesting that, even during adolescence when so much is in flux, Time 1 behavioral intentions continue to remain clasped with their Time 2 counterparts. Indeed, given that driving was not a behavior most participants had engaged in, their intentions were not formed from experience, which may be more adaptable to change based on positive or negative outcomes they counter - for example, having gotten away without being punished or having gotten into a crash. It may well be that, 
for intentions to change substantially, they need to encounter actual experiences and the positive or negative outcomes accompanying them.

Finally, it is worth pointing out that our findings were remarkably similar across males and females. At baseline, our models predicted between 38 (males) and 40 (females) percent of the variance in intentions, and the predictors themselves were remarkably similar. Indeed, a glance at the correlation matrix (Table 4) shows that most of the relationships are similar across males and females. The only significant difference was in the interaction we reported in Figure 1, where improvements in injunctive norms were much more meaningful for males who had been exposed to the campaign.

\section{Limitations}

A significant limitation of our paper is our reliance on self-reports for all our measures. Especially with regard to risk behaviors, the use of self-assessments might be biased due to social desirability concerns (Brener, Billy, \& Grady, 2003). Although the use of the control group mitigates this concern a bit, it is certainly possible that, in the treatment group, knowing we were seeking to change driving behaviors, our participants provided socially desirable responses, something less likely to occur in the control group (where an intervention had not taken place during data collection). This concern is further mitigated by the fact that post-intervention measurements occurred some six months after the intervention. We should also note that, were respondents in the treatment group significantly more likely to exhibit social-desirability biases than those in the control group, such biases would likely be manifest in pro-safety behaviors and attitudes, but we saw differences in both pro-safety as well as high-risk intentions.

Another limitation pertains to attrition. In our longitudinal sample, we encountered approximately 26 percent attrition, which was a surprise to us, given that we returned to the same school during the same academic year. Because we did not collect attendance information, we are unable to account for the high attrition. To make matters worse, attrition 
appears to have been systematic: those who dropped out of the sample at post-intervention were significantly at higher risk than those who remained in the sample in that they had greater intentions to engage in risky behaviors. Because of attrition, the tendency of the overall sample to have been less risk-taking was somewhat attenuated by the fact that the treatment group had higher retention than the control group.

\section{Conclusion}

In order to reach male adolescents, who are at highest risk for automobile crashes and who have remained the most impervious to intervention effects, our findings suggest adopting an approach that improves their injunctive norms and, subsequently, exposes them to the safedriving intervention. Finding creative ways of improving descriptive norms and reducing overconfidence bias also appear to be fruitful strategies for future interventions.

\section{Funding Statement}

This project was funded and run by the World Bank. Two of the authors (RNR, HY) served as consultants to the project. 


\section{References}

Åberg, L. (1993). Drinking and driving: Intentions, attitudes, and social norms of Swedish male drivers. Accident Analysis \& Prevention, 25, 289-296. https://doi.org/10.1016/0001-4575(93)90023-P

Adams, C. E., \& Nagoshi, C. T. (1999). Changes over one semester in drinking game playing and alcohol use and problems in a college student sample. Substance Abuse, 20, 97106. https://doi.org/10.1023/A:1021468400635

Ajzen, I. (1991). The theory of planned behavior. Organizational Behavior and Human Decision Processes, 50, 179-211. https://doi.org/10.1016/0749-5978(91)90020-T

Arnett, J. (1990). Drunk driving, sensation seeking, and egocentrism among adolescents, Personality and Individual Differences, 11, 541-546

Arnett, J. J. (1996). Sensation seeking, aggressiveness, and adolescent reckless behavior. Personality and Individual Differences, 20, 693-702.

Bandura, A. (1986). Social foundations of thought and action. New York: Prentice-Hall.

Baumann, A. O., Deber, R. B., \& Thompson, G. G. (1991). Overconfidence among physicians and nurses: The "micro-certainty, macro-uncertainty" phenomenon. Social Science \& Medicine, 32, 167-174.

Bazargan-Hejazi, S., Teruya, S., Pan, D., Lin, J., Gordon, D., Krochalk, P. C., \& Bazargan, M. (2017). The theory of planned behavior (TPB) and texting while driving behavior in college students. Traffic Injury Prevention, 18, 56-62. https://doi.org/10.1080/15389588.2016.1172703

Beck, K. H. (1981). Driving while under the influence of alcohol: Relationship to attitudes and beliefs in a college population. The American Journal of Drug and Alcohol Abuse, 8, 377-388. https://doi.org/10.3109/00952998109009561 
Berkowitz, A. D. (2004). The social norms approach: Theory, research, and annotated bibliography. Retrieved from http://www.alanberkowitz.com/articles/social_norms.pdf

Brener, N. D., Billy, J. O.G., \& Grady, W. R. (2003). Assessment of factors affecting the validity of self-reported health-risk behavior among adolescents: Evidence from the scientific literature. Journal of Adolescent Health, 33, 436-457. https://doi.org/10.1016/S1054-139X(03)00052-1

Budescu, D. V., \& Rantilla, A. K. (2000). Confidence in aggregation of expert opinions. Acta Psychologica, 104, 371-398.

Cestac, J., Paran, F., \& Delhomme, P. (2011). Young drivers' sensation seeking, subjective norms, and perceived behavioral control and their roles in predicting speeding intention: How risk-taking motivations evolve with gender and driving experience. Safety Science, 49, 424-432. https://doi.org/10.1016/j.ssci.2010.10.007

Chung, A., \& Rimal, R. N. (2016). Social norms: A review. Review of Communication Research, 4, 1-29.

Cialdini, R. B., Reno, R. R., \& Kallgren, C. A. (1990). A focus theory of normative conduct: Recycling the concept of norms to reduce littering in public places. Journal of Personality and Social Psychology, 58, 1015-1026.

Clarke, D. D., Ward, P., \& Truman, W. (2005). Voluntary risk taking and skill deficits in young driver accidents in the UK. Accident Analysis \& Prevention, 37, 523-529. https://doi.org/10.1016/j.aap.2005.01.007

Deery, H. A. (1999). Hazard and risk perception among young novice drivers. Journal of Safety Research, 30, 225-236. https://doi.org/10.1016/S0022-4375(99)00018-3

DeJong, W., Schneider, S. K., Towvim, L. G., Murphy, M., Doerr, E. E., Simonsen, N. R., Mason, K. E., \& Scribner, R. A. (2006). A multisite randomized trial of social norms 
marketing campaigns to reduce college student drinking. Journal of Studies on Alcohol, 67, 868-879.

DeJong, W., Schneider, S. K., Towvim, L. G., Murphy, M., Doerr, E. E., Simonsen, N. R., Mason, K. E., \& Scribner, R. A. (2009). A multisite randomized trial of social norms marketing campaigns to reduce college student drinking: A replication failure. Substance Abuse Journal, 30, 127-140.

DeJoy, D. M. (1989). The optimism bias and traffic accident risk perception. Accident Analysis \& Prevention, 21, 333-340. https://doi.org/10.1016/0001-4575(89)90024-9

DeJoy, D. M. (1990). Gender differences in traffic accident risk perception. Proceedings of the Human Factors Society Annual Meeting, 34, 1032-1036. https://doi.org/10.1177/154193129003401416

DeJoy, D. M. (1992). An examination of gender differences in traffic accident risk perception. Accident Analysis \& Prevention, 24, 237-246. https://doi.org/10.1016/0001$\underline{4575(92) 90003-2}$

Delhomme, P., Verlhiac, J.-F., \& Martha, C. (2009). Are drivers' comparative risk judgments about speeding realistic? Journal of Safety Research, 40, 333-339. https://doi.org/10.1016/j.jsr.2009.09.003

Deutsch, M., \& Gerard, H. B. (1955). A study of normative and informational social influences upon individual judgment. Journal of Abnormal and Social Psychology, 51, $629-636$.

De Wit, J. B., F., Das, E., \& Vet, R. (2008). What works best: Objective statistics or a personal testimonial? An assessment of the persuasive effects of different types of message evidence on risk perception. Health Psychology, 27, 110-115.

Eisenberg, M. E., Toumbourou, J. W., Catalano, R. F., \& Hemphill, S. A. (2014). Social norms in the development of adolescent substance use: A longitudinal analysis of the 
international youth development study. Journal of Youth and Adolescence, 43, 14861497. https://doi.org/10.1007/s10964-014-0111-1

European Commission. (2016). Road Safety: New statistics call for fresh efforts to save lives on EU roads. Retrieved from http://europa.eu/rapid/press-release_IP-16-863_en.htm

Fisher, D. L., Pollatsek, A. P., \& Pradhan, A. (2006). Can novice drivers be trained to scan for information that will reduce their likelihood of a crash? Injury Prevention, 12 Suppl 1, i25-9. https://doi.org/10.1136/ip.2006.012021

Gauld, C. S., Lewis, I., \& White, K. M. (2014). Concealing their communication: Exploring psychosocial predictors of young drivers' intentions and engagement in concealed texting. Accident Analysis \& Prevention, 62, 285-293. https://doi.org/10.1016/j.aap.2013.10.016

Greene, K., Krcmar, M., Rubin, D. L., Walters, L. H., \& Hale, J. L. (2002). Elaboration in processing adolescent health messages: The impact of egocentrism and sensation seeking on message processing. Journal of Communication, 52, 812-831.

Gregersen, N. P. (1996). Young drivers' overestimation of their own skill—an experiment on the relation between training strategy and skill. Accident Analysis \& Prevention, 28, 243-250. https://doi.org/10.1016/0001-4575(95)00066-6

Harré, N. (2000). Risk evaluation, driving, and adolescents: A typology. Developmental Review, 20, 206-226. https://doi.org/10.1006/drev.1999.0498

Harré, N., Field, J., \& Kirkwood, B. (1996). Gender differences and areas of common concern in the driving behaviors and attitudes of adolescents. Journal of Safety Research, 27, 163-173. https://doi.org/10.1016/0022-4375(96)00013-8

Harré, N., Foster, S., \& O’Neill, M. (2005). Self-enhancement, crash-risk optimism and the impact of safety advertisements on young drivers. British Journal of Psychology, 96, 215-230. https://doi.org/10.1348/000712605X36019 
Hittner, J. B., \& Swickert, R. (2006). Sensation seeking and alcohol use: A meta-analytic review. Addictive Behaviors, 31, 1383-1401.

ITF. (2017). Road Safety Annual Report 2017. Paris. Retrieved from OECD Publishing website: http://dx.doi.org/10.1787/irtad-2017-en

Jakobsson, L., Isaksson-Hellman, I., \& Lindman, M. (2008). WHIPS (Volvo cars' whiplash protection system) — the development and real-world performance. Traffic Injury Prevention, 9, 600-605.

Janz, N. K., \& Becker, M. H. (1984). The health belief model: A decade later. Health Education \& Behavior, 11, 1-47. https://doi.org/10.1177/109019818401100101

Jonah, B. A. (1997). Sensation seeking and risky driving: A review and synthesis of the literature. Accident Analysis \& Prevention, 29, 651-665.

Kallgren, C. A., Reno, R. R., \& Cialdini, R. B. (2016). A focus theory of normative conduct: When norms do and do not affect behavior. Personality and Social Psychology Bulletin, 26, 1002-1012. https://doi.org/10.1177/01461672002610009

Kenney, S. R., LaBrie, J. W., \& Lac, A. (2013). Injunctive peer misperceptions and the mediation of self-approval on risk for driving after drinking among college students. Journal of Health Communication, 18, 459-477. https://doi.org/10.1080/10810730.2012.727963

Lapinski, M. L., Rimal. R. N., Klein, K. A., Shulman, H. C. (2009). Risk perceptions of people living with HIV/AIDS: How similarity affects optimistic bias. Journal of Health Psychology, 14, 251-257.

Lewis, M. A., \& Neighbors, C. (2004). Gender-specific misperceptions of college student drinking norms. Psychology of Addictive Behaviors, 18, 334-339. https://doi.org/10.1037/0893-164X.18.4.334 
Mahalik, J. R., Burns, S. M., \& Syzdek, M. (2007). Masculinity and perceived normative health behaviors as predictors of men's health behaviors. Social Science \& Medicine, 64, 2201-2209. https://doi.org/10.1016/j.socscimed.2007.02.035

Massie, D. L., Campbell, K. L., \& Williams, A. F. (1995). Traffic accident involvement rates by driver age and gender. Accident Analysis \& Prevention, 27, 73-87. https://doi.org/10.1016/0001-4575(94)00050-V

Matthews, M. L., \& Moran, A. R. (1986). Age differences in male drivers' perception of accident risk: The role of perceived driving ability. Accident Analysis \& Prevention, 18, 299-313. https://doi.org/10.1016/0001-4575(86)90044-8

McKenna, F. P., \& Myers, L. B. (1997). Illusory self-assessments: Can they be reduced? British Journal of Psychology, 88 (Pt 1), 39-51.

Miller, D. J., Spengler, E. S., \& Spengler, P. M. (2015). A meta-analysis of confidence and judgment accuracy in clinical decision making. Journal of Counseling Psychology, 62, $553-567$.

Møller, M., \& Haustein, S. (2014). Peer influence on speeding behaviour among male drivers aged 18 and 28. Accident Analysis \& Prevention, 64, 92-99. https://doi.org/10.1016/j.aap.2013.11.009

Nemme, H. E., \& White, K. M. (2010). Texting while driving: Psychosocial influences on young people's texting intentions and behaviour. Accident Analysis \& Prevention, 42, 1257-1265. https://doi.org/10.1016/j.aap.2010.01.019

Perkins, H. W., \& Craig, D. A. (2002). A multi-faceted social norms approach to reduce highrisk drinking: Lessons from Hobart and William Smith Colleges. Newton, MA.

Promising Consortium. (1998). PROMISING - Promotion of Measures for Vulnerable Road Users. Retrieved from European Commission website: https://www.nrso.ntua.gr/geyannis/res/rn14-promising-promotion-of-measures-with- 
regard-to-mobility-integrated-with-safety-taking-into-account-the-inexperience-ofvulnerable-user-groups/

Rhodes, N., \& Pivik, K. (2011). Age and gender differences in risky driving: The roles of positive affect and risk perception. Accident Analysis \& Prevention, 43, 923-931. https://doi.org/10.1016/j.aap.2010.11.015

Rimal, R. N., \& Lapinski, M. K. (2015). A re-explication of social norms, ten years later. Communication Theory, 25, 393-409. https://doi.org/10.1111/comt.12080

Rimal, R. N., Lapinski, M., Cook, R., \& Real, K. (2005). Moving toward a theory of normative influences: How perceived benefits and similarity moderate the impact of descriptive norms on behaviors. Journal of Health Communication, 10, 433-450.

Rimal, R. N., \& Morrison, D. (2006). A uniqueness to personal threat (UPT) hypothesis: How similarity affects perceptions of susceptibility and severity in risk assessment. Health Communication, 20, 209-219.

Rimal, R. N., \& Real, K. (2005). How behaviors are influenced by perceived norms: A test of the theory of normative social behavior. Communication Research, 32, 389-414. https://doi.org/10.1177/0093650205275385

Road Safety Agency (RSA; 2015). Statistical report on the state of traffic safety in the Republic of Serbia for the year 2014. Road Safety Agency: Belgrade.

Rogers, R. W. (1983). Cognitive and physiological processes in fear appeals and attitude change: a revised theory of protection motivation. In J. T. Cacioppo \& R. E. Petty (Eds.), Social psychology. New York: Guilford.

Rosenstock, I. M. (1974). Historical origins of the health belief model. Health Education Monographs, 2, 328-335. https://doi.org/10.1177/109019817400200403

Sallis, J., \& Owen, N. (2015). Ecological models of health behavior. In K. Glanz, B. Rimer, and K. Viswanath (Eds.), Health behavior, $5^{\text {th }}$ ed. (pp. 43-64). Wiley: New York. 
Santamariña-Rubio, E., Pérez, K., Olabarria, M., \& Novoa, A. M. (2014). Gender differences in road traffic injury rate using time travelled as a measure of exposure. Accident Analysis \& Prevention, 65, 1-7. https://doi.org/10.1016/j.aap.2013.11.015

Shulman, H. C., Rhodes, N., Davidson, E., Ralston, R., Borghetti, L., \& Morr, L. (2017). The state of the field of social norms research. International Journal of Communication, $11,1192-1213$.

Simons-Morton, B. G., Ouimet, M. C., Chen, R., Klauer, S. G., Lee, S. E., Wang, J., \& Dingus, T. A. (2012). Peer influence predicts speeding prevalence among teenage drivers. Journal of Safety Research, 43, 397-403. https://doi.org/10.1016/j.jsr.2012.10.002

Spence, M. T. (1996). Problem-problem solver characteristics affecting the calibration of judgments. Organizational Behavior and Human Decision Processes, 67, 271-279.

Tränkle, U., Gelau, C., \& Metker, T. (1990). Risk perception and age-specific accidents of young drivers. Accident Analysis \& Prevention, 22, 119-125. https://doi.org/10.1016/0001-4575(90)90063-Q

Treviño-Siller, S., Pacheco-Magaña, L. E., Bonilla-Fernández, P., Rueda-Neria, C., \& ArenasMonreal, L. (2017). An educational intervention in road safety among children and teenagers in Mexico. Traffic Injury Prevention, 18, 164-170. https://doi.org/10.1080/15389588.2016.1224344

Turner, C., \& McClure, R. (2003). Age and gender differences in risk-taking behaviour as an explanation for high incidence of motor vehicle crashes as a driver in young males. Injury control and safety promotion, 10, 123-130. https://doi.org/10.1076/icsp.10.3.123.14560

Ulen, T. S. (2005). Human fallibility and the forms of law: The case of traffic safety. In F. Parisi and V. L. Smith (Eds.), The law and economics of irrational behavior (pp. 397421). Stanford University Press: Stanford, CA. 
Viano, D. C. (2003). Seat influences on female neck responses in rear crashes: A reason why women have higher whiplash rates. Traffic Injury Prevention, 4, 228-239.

Wagenaar, W. A., \& Keren, G. B. (1985). Calibration of probability assessments by professional blackjack dealers, statistical experts, and lay people. Organizational Behavior and Human Decision Processes, 36, 406-416

Weinstein, N. D. (1982). Unrealistic optimism about susceptibility to health problems. Journal of Behavioral Medicine, 5, 441-460.

Weinstein, N. D. (1987). Unrealistic optimism about susceptibility to health problems: Conclusions from a community-wide sample. Journal of Behavioral Medicine, 10, 481-500. https://doi.org/10.1007/BF00846146

Weinstein, N. D., \& Nicolich, M. (1993). Correct and incorrect interpretations of correlations between risk perceptions and risk behaviors. Health Psychology, 12, 235-245.

White, M. J., Cunningham, L. C., \& Titchener, K. (2011). Young drivers' optimism bias for accident risk and driving skill: Accountability and insight experience manipulations. Accident Analysis \& Prevention, 43, 1309-1315. https://doi.org/10.1016/j.aap.2011.01.013

Witte, K. (1992). Putting the fear back in fear appeals: The extended parallel process model. Communication Monographs, 59, 330-349.

World Health Organization (WHO; 2015). Global status report in road safety 2015. Retrieved from http://www.who.int/violence_injury_prevention/road_safety_status/2015/en/

World Health Organization (WHO; 2017). Road traffic injuries: Fact sheet. Retrieved from http://www.who.int/mediacentre/factsheets/fs358/en/

Zhang, L., Wieczorek, W. F., \& Welte, J. W. (2012). The influence of parental and peer drinking behaviors on underage drinking and driving by young men. Journal of Drug Education, 42, 347-359. https://doi.org/10.2190/DE.42.3.f 
Zuckerman, M. (1979). Sensation seeking: Beyond the optimum level of arousal. Hillsdale, NJ: Lawrence Erlbaum Associates. 


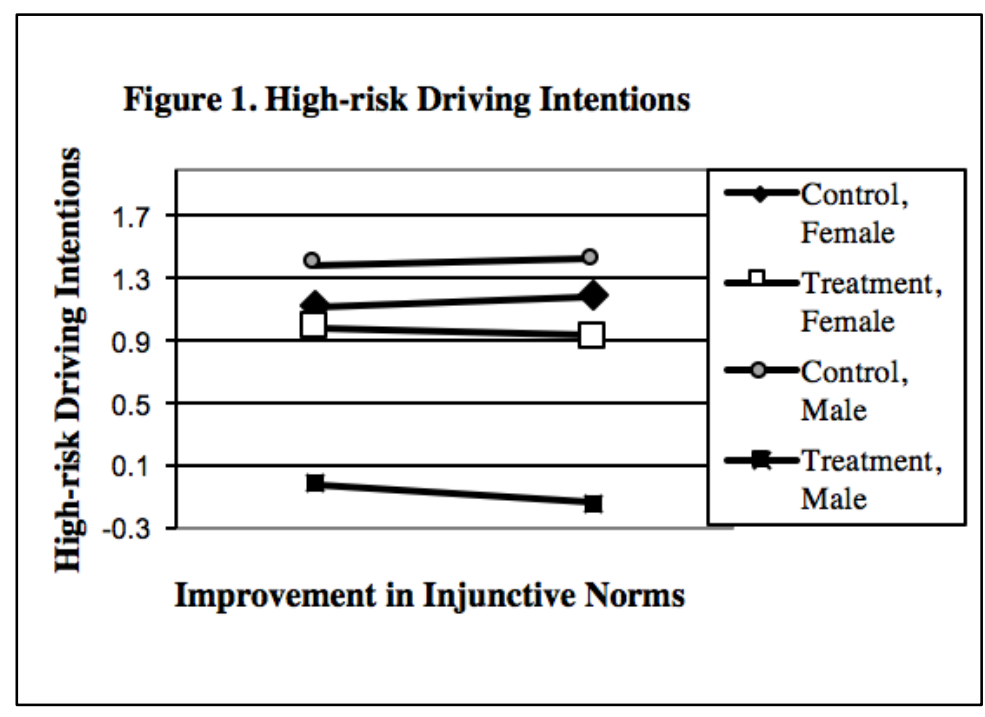




\begin{tabular}{|c|c|c|c|}
\hline & $\begin{array}{c}\text { Treatment } \\
N=664\end{array}$ & $\begin{array}{l}\underline{\text { Control }} \\
N=785\end{array}$ & \\
\hline Respondent Characteristics & $M(\mathrm{SD})$ & $M(\mathrm{SD})$ & $t$ \\
\hline \multirow[t]{2}{*}{ Age } & $17.92(0.73)$ & $17.95(0.75)$ & 0.69 \\
\hline & $\%$ & $\%$ & Chi-sq \\
\hline Gender & & & 0.09 \\
\hline Male & 48.6 & 49.4 & \\
\hline Female & 51.4 & 50.6 & \\
\hline Owning a License & 11.4 & 12.1 & 0.20 \\
\hline Driving a Car & 22.5 & 23.2 & 0.12 \\
\hline Exposure to Campaign & 87.9 & 84.6 & 3.36 \\
\hline Has been in a crash or has had & 53.6 & 56.6 & 1.31 \\
\hline friends or family in a crash & & & \\
\hline
\end{tabular}

Note: None of the tests shown above were statistically significant 


\section{Baseline}
Males
Females

Predictors

$\beta$

$\beta$

Age

$-.04$

$-.04$

Owning a license

$-.03$

$-.06$

Driving a car

$-.09 *$

$-.02$

Risk perception ${ }^{\mathrm{a}}$

$-.17 * * *$

$-.16^{* * *}$

Overconfidence bias ${ }^{b}$

$.25 * * *$

$.39 * * *$

Descriptive norms ${ }^{\mathrm{c}}$

$-.34 * * *$

$-.27 * * *$

Injunctive norms ${ }^{\mathrm{d}}$

$-.01$

$-.02$

(Adjusted R-squared, \%)

(37.8)

(40.7)

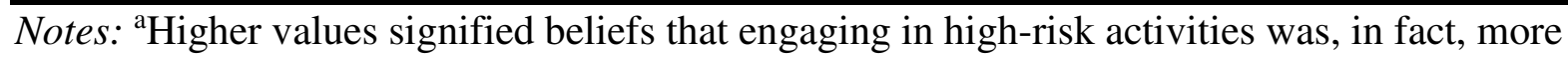
risky. 'Higher values signified greater overconfidence in one's ability to get away with highrisk activities. 'Higher values signified that one's friends engaged in fewer risky behaviors. 'Higher values signified that one's friends would be upset if one's driving behaviors were risky. $* p<.05, * * p<.01, * * * p<.001$ 


\begin{tabular}{|c|c|c|c|c|c|c|c|c|}
\hline & & \multicolumn{3}{|c|}{ Treatment Schools } & \multicolumn{3}{|c|}{ Control Schools } & \multirow[b]{2}{*}{$t_{\Delta \mathrm{T}-\Delta \mathrm{C}}$} \\
\hline & & $\underline{\text { Pre }}$ & $\underline{\text { Post }}$ & $t_{\Delta T}$ & $\underline{\text { Pre }}$ & $\underline{\text { Post }}$ & $t_{\Delta \mathrm{C}}$ & \\
\hline \multicolumn{9}{|c|}{ Male Students } \\
\hline \multirow[t]{2}{*}{ Risk perception } & $M$ & 3.38 & 3.46 & 1.65 & 3.21 & 3.17 & 0.96 & $1.87 *$ \\
\hline & $S D$ & 0.72 & 0.80 & & 0.73 & 0.82 & & \\
\hline \multirow[t]{2}{*}{ Overconfidence bias } & $M$ & 2.66 & 2.71 & 0.77 & 2.76 & 2.83 & 1.31 & 0.32 \\
\hline & $S D$ & 0.89 & 0.84 & & 0.87 & 0.96 & & \\
\hline \multirow[t]{2}{*}{ Descriptive norms } & $M$ & 3.44 & 3.40 & .60 & 3.42 & 3.45 & 0.62 & 0.86 \\
\hline & $S D$ & 0.94 & 0.87 & & 0.93 & 0.92 & & \\
\hline \multirow[t]{2}{*}{ Injunctive norms } & $M$ & 2.86 & 2.99 & $1.73 *$ & 2.87 & 3.03 & $2.11 * *$ & 0.30 \\
\hline & $S D$ & 1.04 & 0.92 & & 0.99 & 1.05 & & \\
\hline \multicolumn{9}{|c|}{$\underline{\text { Female Students }}$} \\
\hline \multirow[t]{2}{*}{ Risk perception } & $M$ & 3.41 & 3.47 & $1.68 *$ & 3.42 & 3.38 & 1.15 & $2.0 * *$ \\
\hline & $S D$ & 0.63 & 0.70 & & 0.73 & 0.77 & & \\
\hline \multirow[t]{2}{*}{ Overconfidence bias } & $M$ & 2.53 & 2.49 & 0.94 & 2.43 & 2.49 & 1.22 & 1.53 \\
\hline & $S D$ & 0.75 & 0.78 & & 0.77 & 0.80 & & \\
\hline \multirow[t]{2}{*}{ Descriptive norms } & $M$ & 3.23 & 3.35 & $2.18 * *$ & 3.40 & 3.46 & 0.98 & 0.75 \\
\hline & $S D$ & 0.91 & 0.89 & & 0.93 & 1.00 & & \\
\hline \multirow[t]{2}{*}{ Injunctive norms } & $M$ & 3.01 & 3.18 & $3.05 * *$ & 3.05 & 3.07 & 0.34 & $1.86^{*}$ \\
\hline & $S D$ & 0.97 & 0.91 & & 0.88 & 0.98 & & \\
\hline
\end{tabular}

Notes: The first $t$-test assesses the difference between pre and post scores in treatment schools, the second $t$-test assesses the difference between pre and post scores in control schools, and the third $t$-test assesses the difference in treatment schools against the difference 
in control schools. Because of the directional hypothesis, one-tailed tests are reported. ${ }^{*} p<$ $.05, * * p<.01, * * * p<.001$. 
Table 4. Zero-Order Pearson Correlations among Psychosocial Factors and High-Risk

Driving Intentions (Male scores below the diagonal and female scores above the diagonal)
(1)
(2)
(3)
(4)
(5)
(6)
(7)

\begin{tabular}{lccccccc}
\hline 1. (Pre) Intentions & $\mathbf{1 . 0 0}$ & .08 & $-.16^{* * *}$ & $.09 *$ & -.07 & .06 & $.50 * * *$ \\
2. $\Delta$ Perceived risk & .05 & $\mathbf{1 . 0 0}$ & $-.26^{* * *}$ & .08 & $.09 *$ & $.08 *$ & -.04 \\
3. $\Delta$ Overconfidence bias & $-.09 *$ & $-.26 * * *$ & $\mathbf{1 . 0 0}$ & $-.38^{* * *}$ & .04 & -.07 & $.20 * * *$ \\
4. $\Delta$ Descriptive norms & $.17 * * *$ & $.11^{*}$ & $-.36^{* * *} \mathbf{1 . 0 0}$ & .00 & .03 & $-.14 * * *$ \\
5. $\Delta$ Injunctive norms & .05 & $.26 * * *$ & $-.15^{* * *} .08$ & $\mathbf{1 . 0 0}$ & .08 & -.02 \\
6. Treatment & -.04 & .08 & -.01 & -.04 & -.01 & $\mathbf{1 . 0 0}$ & -.08 \\
7. (Post) Intentions & $.52 * * *$ & -.05 & $.22 * * *$ & $-.14 * *$ & -.08 & -.02 & $\mathbf{1 . 0 0}$ \\
\end{tabular}

Notes: All change scores (designated by $\Delta$ ) were calculated by subtracting the preintervention scores from the post-intervention scores. ${ }^{*} p<.05,{ }^{* *} p<.01, * * * p<.001$ 
Table 5. Multivariate Predictors of Intention to Engage in High-Risk Driving Behaviors at Post-Intervention from Hierarchical Regression Equations

\begin{tabular}{|c|c|c|c|c|}
\hline \multirow[b]{2}{*}{ Predictors } & \multicolumn{2}{|c|}{ Males } & \multicolumn{2}{|c|}{ Females } \\
\hline & $\beta^{\mathrm{a}}$ & $\Delta \mathrm{R}^{2}$ & $\beta^{\mathrm{a}}$ & $\Delta \mathrm{R}^{2}$ \\
\hline
\end{tabular}

Step 1: Baseline intentions

$.60 * * * \quad .298 * * *$

$.57 * * * \quad .267 * * *$

Step 2: Demographics

.008

.007

Age

.01

$-.02$

Owning a license

.08

.08

Driving a car

.05

$-.01$

Step 3: Psychosocial factors

$.097 * * *$

$.11 * * *$

$\Delta$ Risk perception ${ }^{\mathrm{a}}$

$-.01$

.01

$\Delta$ Overconfidence bias ${ }^{\mathrm{b}}$

$.21 * * *$

$.25 * * *$

$\Delta$ Descriptive norms ${ }^{\mathrm{c}}$

$-.15^{* * *}$

$-.11 * *$

$\Delta$ Injunctive norms $^{\mathrm{d}}$

$-.06$

.01

Step 4: Treatment

$-.02 \quad .001$

$-.09 *$

.000

Step 5: Interactions

Treatment x $\Delta$ Injunctive norms -..11* .006*

$-.10 * \quad .005^{*}$

(Total adjusted R-squared)

(.397)

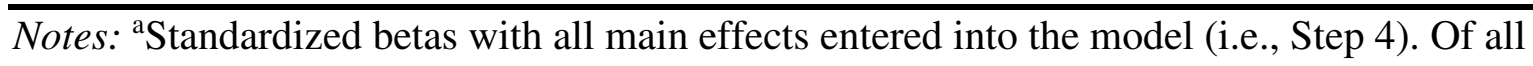
psychosocial factors-by-treatment terms tested, only the treatment $\mathrm{x}$ change in injunctive norms interaction term was significant. All change scores (designated by $\Delta$ ) were computed by subtracting pre-intervention scores from post-intervention scores. $* p<.05$, $* * p<.01, * * * p$ $<.001$ 